\title{
Hereditary Cup-shaped Ears and the Pierre Robin Syndrome*
}

\author{
DALE M. PETERSON and R. NEIL SCHIMKE $†$
}

From the Department of Medicine, University of Kansas Medical Center, Kansas City, Kansas 66103, U.S.A.

Malformations of the external ear are frequently observed in clinical practice, usually as an isolated finding without any significant family history. In 1937, Potter reported a five generation pedigree in which 22 people were affected with a cup-shaped ear deformity or 'cat's ear' (Potter, 1937). Subsequently, three other families with similar anomalies have been recorded (Grotting, 1958; Romei, 1959; Erich and Abu-Jamra, 1965), and pedigree analysis indicated that the cup-shaped ear was inherited as an autosomal dominant trait. No other consistent abnormalities have been present in these families and there has been no associated deafness.

Recently, we have had the opportunity to study a family in which a minimum of 12 members in 5 generations were affected with cup-shaped ears. Of further interest was the fact that the proband had the Pierre Robin syndrome in addition to the ear anomaly.

\section{Case Report}

The proband (VI.2, Fig. 1), a 23-month-old Caucasian female, was the product of a full-term spontaneous delivery without gestational complications. At birth she was noted to have considerable respiratory difficulty due to micrognathia and glossoptosis. She also had a bilateral cleft palate and bilateral cup-shaped external ears. The pinnae were small, and inverted, and the helix extended over the scaphoid fossa (Fig. 2). Perception of auditory stimuli was intact and the remainder of the physical examination was unremarkable. A feeding gastrostomy was constructed shortly after birth, and the infant's position was carefully controlled to avoid respiratory embarrassment. Her subsequent growth and development have been normal, and she has had an uneventful surgical repair of the cleft palate. In view of the potential association between abnormal external ears

\footnotetext{
Received July 4, 1967.

* This investigation was supported in part by a contribution from the El Dorado United Fund.

t Reprint requests to Dr. Schimke.
}

and renal agenesis, intravenous pyelograms were performed on the child and her mother: both were normal.

The bilaterally deformed ears have been traced through five generations on the maternal side of the family to an orphan girl of German descent. With the exception of the proband, no other significant abnormality has been found in association with the ear deformity on the maternal side of the family. The family contains 12 definitely affected members and 9 other members who were probably affected, but who were not examined personally or whose photographs were not available. The presence of deformed ears in the deceased members was determined by history and by examination of family picture albums. Although there was considerable variation in the shape of the abnormal ears within the family, affected subjects were easily identified (Fig. 3). Subjects VI.1, 2, 3, 4, 5; V.1, 2, 8, $10,11,13,14,15,16$; IV.1, 3, 4, and 5 were tested for $\mathrm{ABO}, \mathrm{Rh}, \mathrm{MNSs}, \mathrm{Fy}^{\mathrm{a}}, \mathrm{Jk}^{\mathrm{a}}, \mathrm{Jk}^{\mathrm{b}}, \mathrm{P}, \mathrm{Le}^{\mathrm{a}}$, and $\mathrm{Le}^{\mathrm{b}}$ blood groups. As was expected, in view of the small number of those definitely affected, there was no good evidence for or against linkage of the gene determining the cup-shaped ear and any of the 'marker' genes.

\section{Discussion}

The external ear begins to differentiate during the sixth week of intrauterine life. Initially six small tubercles appear, three on the caudal border of the first branchial arch and three on the second arch. These six primordial parts subsequently combine and gradually develop to the adult auricular shape over the next few weeks (Arey, 1965). Persistence of the foetal ear structure or cup-shaped ears were first noted to be inherited in 1937 by Potter, and since that time only three other families have been described in addition to the present one. Review of the affected families suggested that the defective gene had a restricted action, apparently by arresting development of only the external ear sometime between the sixth and tenth week of foetal life.

The additional feature of the Pierre Robin syndrome in the proband has been somewhat confusing. 52 


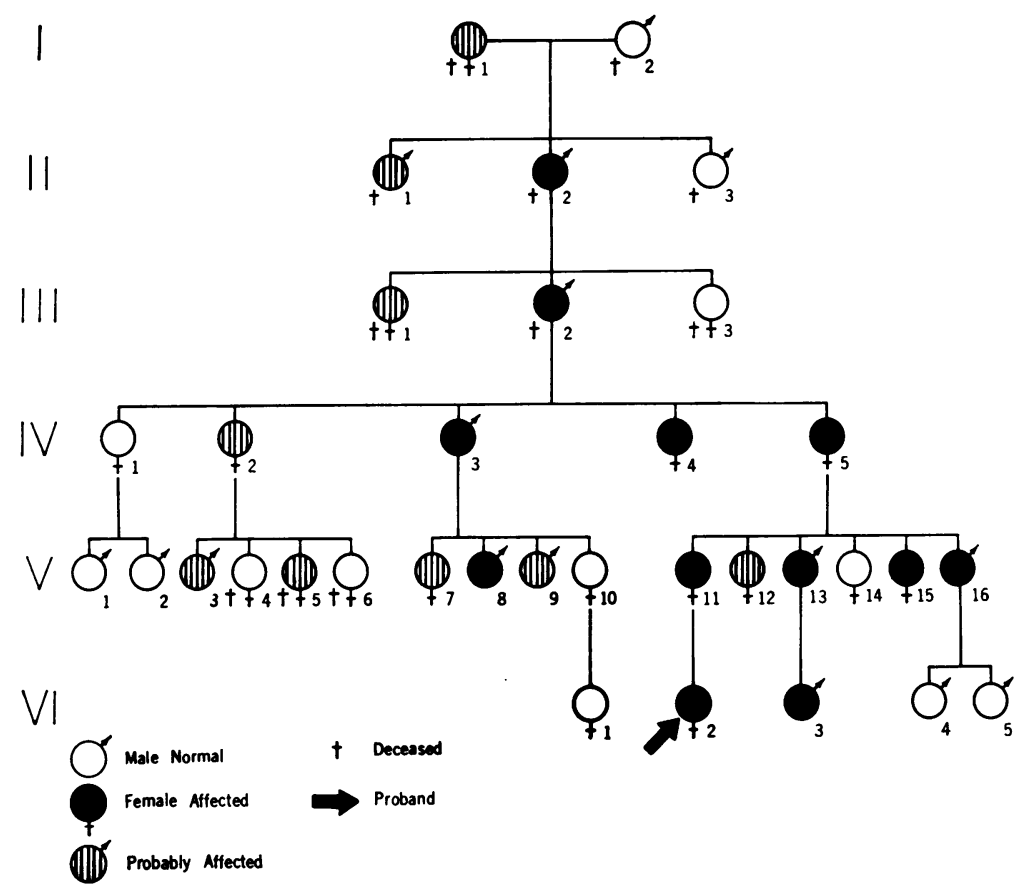

FIG. 1. The pedigree. Five generations have been definitely affected, and four instances of male transmission have been observed. These findings are consistent with autosomal dominant inheritance.

second arch derivatives are probably multifactorial in aetiology, with both genetic and environmental factors playing an inseparable role. Indeed, a recurrence risk for branchial arch defects in subsequent sibs has been quoted as $2 \%$ (Grabb, 1965), a figure compatible with multifactorial inheritance. In contrast, McKenzie (1966) has proposed that mandibulo-facial dysostosis, the Pierre Robin syndrome, deformities of the external and middle ear, congenital deafness, hypertelorism, cleft lip, and cleft palate be assigned to a 'first arch syndrome'. He suggested that the development of this syndrome might be dependent upon an anomalous stapedial artery inherited as autosomal dominant trait with

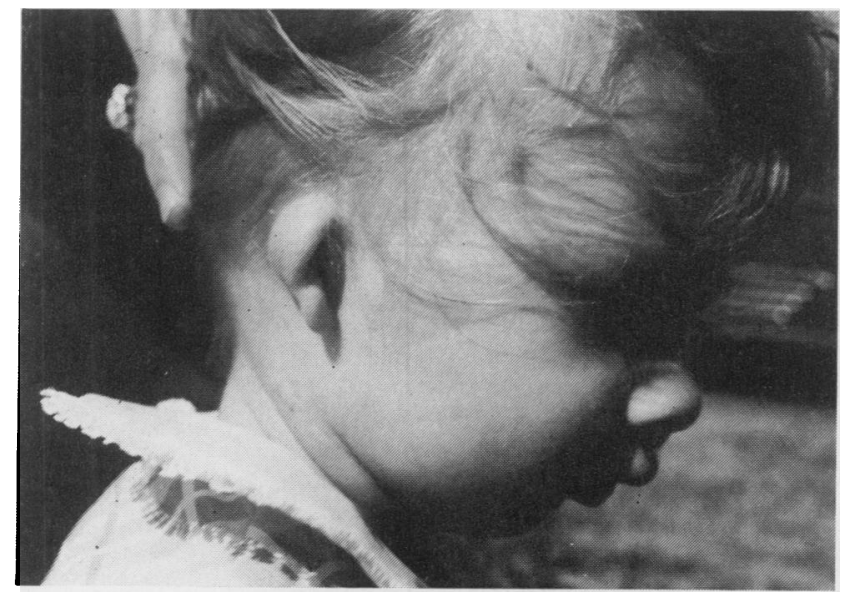

Fig. 2. Note the cup-shaped ear and the persistent micrognathia in the proband. The opposite ear has an identical configuration. 
FIG. 3. This figure shows the range of variability among those affected with the cup-shaped ear.

moderate penetrance and variable expression. However, the number of people at risk in the present family who have only abnormal external ears is probably too high to be accounted for simply by a variably expressed dominant gene. Furthermore, while a more comprehensive gene defect may be operative in some families, it is quite likely that in others single gene defects are more limited in their phenotypic expression. For example, mandibulofacial dysostosis has been reported to be inherited as an autosomal dominant trait (Fazen, Elmore, and Nadler, 1967). Cleft lip with or without cleft palate, often the result of multiple factors, has been recorded in five consecutive generations (Test and Falls, 1947). For isolated midline cleft palate, both autosomal dominant (Gorlin and Pindborg, 1964) and X-linked inheritance (Weinstein and Cohen, 1966) have been offered. Cleft palate has also been reported in association with lip pits over three generations (Levy, 1962), and branchial cleft anomalies, including cysts, sinuses, and skin tags have been seen in one family in a pattern consistent with autosomal dominant inheritance (Wheeler, Shaw, and Cawley, 1958). The Pierre Robin syndrome, while usually an isolated developmental event, has been reported in more than one family member (Smith and Stowe, 1961; Sachtleben,

1964). In one of these families (Smith and Stowe, 1961) other relatives had partial manifestations of the syndrome, and the possibility of dominant inheritance has been raised (McKusick, 1966). In this regard it is of interest that several members of the paternal side of the present family, including the father of the proposita, had relative micrognathia at birth. No one had a defect as marked as the proband, and there was no further history of cleft palate or respiratory difficulty. However, it is tempting to speculate that our case suffered from two genetic defects, one the result of a completely penetrant autosomal dominant gene with an effect limited to the ear, and the other secondary to a variably expressed gene producing a more significant imbalance in the development of the first and second branchial arches, resulting in the Pierre Robin syndrome.

The assimilation of branchial arch defects under a single heading, while possibly useful from a diagnostic and therapeutic standpoint, tends to obscure rather than clarify gene action in embryogenesis. It is quite likely that a collection of simply inherited first and second arch syndromes exist that are genetically distinct, yet have considerable phenotypic overlap. Careful embryological study of various experimental animals may be helpful in understanding the pathogenesis of these syndromes. Moreover, close attention to minor malformations in other family members may assist not only in the elucidation of genetic heterogeneity, but may help to define better the relative contribution of heredity and environment in the aetiology of congenital malformations of the head and neck.

\section{Summary}

Five generations of a family affected with hereditary cup-shaped ears are reported. The proband had the Pierre Robin syndrome as an additional feature. The possible relation between these two disorders is discussed within the framework of the development of the first and second branchial arches. It is concluded that a number of branchial arch syndromes exist that are genetically distinct and simply inherited yet have considerable phenotypic overlap.

The authors would like to thank W. G. Chappuie for bringing this family to our attention.

\section{REFERENCES}

Arey, L. B. (1965). Developmental Anatomy, p. 548. W. B. Saunders, Philadelphia.

Erich, J. B., and Abu-Jamra, F. N. (1965). Congenital cup-shaped deformity of the ears transmitted through four generations. Mayo Clin. Proc., 40, 597. 
Fazen, L. E., Elmore, J., and Nadler, H. L (1967). Mandibulofacial dysostosis. Amer. 7. Dis. Child., 113, 405.

Gorlin, R. J., and Pindborg, J. J. (1964). Syndromes of the Head and Neck, p. 96. McGraw-Hill, New York.

Grabb, W. C. (1965). The first and second branchial arch syndrome. Plast. reconstr. Surg., 36, 485.

Grotting, J. K. (1958). Otoplasty for congenital cupped protruding ears using a post-auricular flap. ibid., 22, 164

Levy, J. (1962). Zwillinge in einer Familie mit UnterlippenMissbildung. Acta genet. (Basel), 12, 33.

McKenzie, J. (1966). The first arch syndrome. Develop Med. Child Neurol., 8, 55.

McKusick, V. A. (1966). Mendelian Inheritance in Man, p. 226. Johns Hopkins Press, Baltimore.

Potter, E. L. (1937). A hereditary ear malformation transmitted through five generations. F. Hered., 28, 255.
Romei, L. (1959). Una famiglia con conformazione del padiglione auricolare del tipo di Potter (cup-shaped ear). Acta Genet. med. (Roma), 8, 483.

Sachtleben, P. (1964). Zur Pathogenese und Therapie des PierreRobin Syndroms. Arch. Kinderheilk., 171, 55.

Smith, J. L., and Stowe, F. R. (1961). The Pierre-Robin syndrome (glossoptosis, micrognathia, cleft palate). Pediatrics, 27, 128.

Test, A. R., and Falls, H. F. (1947). Dominant inheritance of cleft lip and palate in five generations. F. oral Surg., 5, 292.

Weinstein, E. D., and Cohen, M. M. (1966). Sex-linked cleft palate. Report of a family and review of 77 kindreds. $f$. med. Genet., 3, 17.

Wheeler, C. E., Shaw, R. F., and Cawley, E. P. (1958). Branchial anomalies in three generations of one family. Arch. Derm., 77, 715 . 